\title{
VIOLÊNCIA OBSTÉTRICA: como o mito "parirás com dor" afeta a mulher brasileira
}

Sarah Pereira ALVARENGA ${ }^{1}$

José Helvécio KALIL²

\author{
${ }^{1}$ Aluna do curso de Graduação em Medicina da Faculdade Faminas unidade Belo Horizonte \\ ${ }^{2}$ Professor Mestre em Ginecologia e Obstetrícia (UFMG), Doutor em Reprodução Humana (UFMG), Especialista em \\ Oncologia Ginecológica e Biodireito \\ Endereço para correspondência do autor: Sarah Pereira Alvarenga
}

Rua: Hermilo Alves, 400 casa. Bairro: Santa Teresa CEP: 31010-070 Belo Horizonte, Minas Gerais - Brasil E-mail: sarahalvarenga610@hotmail.com

\section{Recebido em: 26/01/2016 - Aprovado em: 15/08/2016 - Disponibilizado em: 18/12/2016}

\section{RESUMO:}

O objetivo deste artigo foi analisar e compilar trabalhos, que evidenciam aspectos culturais que fazem com que a violência obstétrica esteja tão presente no Brasil. Trata-se de uma pesquisa qualitativa com referencial téoricometodológico retirado de pesquisas bibliográficas, em materiais publicados na internet. Foi constatado que grande parte das violências obstétricas ocorridas no país não são devidamente julgadas por falta de informação por parte da própria mulher que sofreu a agressão. Dessa forma, a ignorância sobre seus direitos se mostrou o maior aliado para a ocorrência desse fato.

Palavras Chave: Violência obstétrica. Parto seguro. Direitos da parturiente. Ginecologia. Parto no Brasil

\section{OBSTETRIC VIOLENCE: how the myth "in pain you will give birth" affects the brazilian woman}

\begin{abstract}
:
The aim of this article is to analyze and compile works, which highlight the cultural aspects that make the obstetric violence to be so present in Brazil. This is a qualitative paper, with a theoretical-methodologic referential, which was taken out from bibliographic researches and internet publications. It was noticed that the majority of the obstetric violence occurred in this country were not appropriately judged by lack of information by the injured woman. This way, the unknowledge by women of their rights was considered the major factor of the abuse occurrence.

Keywords: Obstetric violence; Safe childbirth; Parturient rights; Gynecology. Birth in Brazil.
\end{abstract}

\section{Introdução}

Até o século XVIII, o parto era considerado um ritual entre as mulheres e não um ato médico, já que o momento ficava a cargo das parteiras. Já no final do século XIX, os obstetras passaram a transformar o parto em um evento controlado, o que só se efetivou na metade do século $\mathrm{XX}$, no qual o cenário do parto domiciliar foi se alterando e sendo extinto na sociedade.

A criação de hospitais específicos para a realização do parto - as maternidades - foi 
um evento do fim do século XIX. A construção de maternidades tinha como objetivo criar tanto um espaço de ensino e prática da medicina como um lugar onde as mulheres sentissem segurança para parir.

No entanto, essa segurança para parir não tem sido uma realidade no Brasil. Isso porque, de acordo com a pesquisa "Mulheres brasileiras e gênero nos espaços público e privado", divulgada em 2010 pela Fundação Perseu Abramo, uma em cada quatro mulheres sofre algum tipo de violência durante o parto.

Esse número, provavelmente, é ainda maior. Isso porque a maior parte das mulheres não tem conhecimento dos seus direitos e não sabem ao certo o que pode ou não, ser considerada uma violência obstétrica.

É considerada violência obstétrica desde a enfermeira que pede para a mulher não gritar na hora do parto normal até o médico que faz uma episiotomia indiscriminada - o corte entre o ânus e a vagina para facilitar a saída do bebê. Apesar de a OMS (Organização Mundial da Saúde) determinar critérios e cautela para a adoção do procedimento, médicos fazem a prática de maneira rotineira. A obstetriz Ana Cristina Duarte, do GAMA (Grupo de Maternidade Ativa), estima que entre $80 \%$ a $90 \%$ das brasileiras são cortadas durante o parto normal. "Sabemos que há evidências de que não é necessário mais cortar as mulheres. As mulheres são cortadas sem o consentimento delas e isso é uma violência obstétrica", comenta.

As consequências dos desrespeitos sofridos pela mulher durante o trabalho de parto são muitas, desde cicatrizes a traumas emocionais. Algumas dessas consequências foram enumeradas pela psicóloga Vera Laconelli, diretora do Instituto Brasileiro de

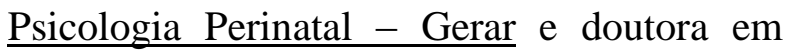
psicologia pela Universidade de São Paulo. “Os sintomas podem ser vários, como não conseguir mais ter relações sexuais com o marido, ter uma depressão pós-parto, pesadelos, entre outros".

\section{Objetivos}

\section{Objetivo geral}

O presente trabalho tem como objetivo demonstrar que, apesar da violência obstétrica ser extremamente comum no Brasil, poucas mulheres sabem o que pode ser considerado uma violência e quais são os seus direitos.

\section{Objetivos específicos}

Expor quais atos podem ser considerados uma violência obstétrica.

Expor, através de dados, a grande quantidade de violência obstétrica que ocorre no Brasil todos os anos.

Analisar o papel do médico especialista e equipe multidisciplinar na abordagem da violência obstétrica. 
Expor quais são os direitos da mulher parturiente.

Demonstrar que a falta de informação facilita o desrespeito das normas estabelecidas pela OMS.

Informar a mulher quais medidas devem ser tomadas, caso ela sofra violência obstétrica.

\section{Metodologia}

Trata-se de uma pesquisa qualitativa com referencial téorico-metodológico retirado de pesquisas bibliográficas, em materiais publicados na internet. Foram selecionados artigos publicados entre os anos de 2000 e 2014 com o objetivo de pesquisar a trajetória da violência obstétrica no Brasil e como as mulheres têm reagido em relação a ela. Foi utilizado o site de buscas Scielo com o uso das palavras chave violência obstétrica, parto seguro, direitos da parturiente e ginecologia. Foram analisados textos de autores de várias áreas da saúde, como enfermeiros, médicos, fisioterapeutas e terapeutas ocupacionais, com o objetivo de contemplar vários pontos de vista diferentes.

\section{Referencial Teórico}

A violência obstétrica já fez parte da realidade de grande parte das parturientes do Brasil. Infelizmente, $25 \%$ das mulheres que tiveram filhos pelas vias naturais na rede pública e privada sofreram violência obstétrica no país, de acordo com uma pesquisa da Fundação Perseu Abramo. Apesar de a pesquisa se restringir ao parto normal, a violência também pode acontecer em uma cesárea.

De acordo com Neuma Zamariano (2006), mestre docente da disciplina sexualidade e reprodução Humana, da faculdade de enfermagem da Universidade Federal do Mato Grosso, "No século XIX a vivência do parto e tudo o que nele ocorria era aceito pelas mulheres como uma fatalidade, algo do qual não se podia fugir. Era uma vivência privada da mulher que paria com o apoio de outras mulheres, que faziam todos os esforços para que a parturiente tivesse o maior conforto possível durante o evento. Havia uma cultura de solidariedade feminina profundamente associada ao processo de nascer, o que lhe conferia o status de ser esse um evento doméstico, onde a dor podia ser inevitável, mas o entorno era de apoio e compreensão".

A realidade hoje é bem diferente em relação à vivência do parto. Segundo Vera Laconelli “A figura da parturiente na nossa cultura é muito idealizada, imagina-se que a mulher será como uma Virgem Maria parindo e quando ela não corresponde a essa expectativa vem um terrível ódio". Esse ódio e desrespeito são praticados pelos profissionais da saúde que a mulher tanto confiou para auxiliar no momento que seria o mais feliz de sua vida. 
Alguns exemplos de violência obstétrica são a infusão intravenosa para acelerar o trabalho de parto (ocitocina sintética), a pressão sobre a barriga da parturiente para empurrar o bebê (manobra de Kristeller), o uso rotineiro de lavagem intestinal, retirada dos pelos pubianos (tricotomia) e exame de toque frequente para verificar a dilatação. São comuns também os relatos de humilhações praticados por parte dos profissionais de saúde que dizem frases como "se você não parar de gritar, eu não vou mais te atender", "na hora de fazer não gritou" e outras do gênero.

Ainda de acordo com Laconelli, "As mulheres não conseguem reconhecer a violência, pois já estão muito ligadas a um certo lugar da mulher na cultura. A mulher está acostumada ao corpo dela ficar muito à mercê do outro. Só na medida em que elas descobrem que o parto poderia ser de outra forma é que compreendem o que sofreram”.

Os exemplos, de violência sofrida pelas mulheres, são inúmeros. No entanto, a médica e pesquisadora Vilma de Carvalho salienta que o desrespeito não ocorre somente com as mulheres:

O desrespeito ocorre com a mulher que é agredida, privada de água e alimentação, tem a vagina cortada como procedimento padrão sem avaliar a real necessidade, ou que é induzida a uma cirurgia sem necessidade, mas também com o bebê que muitas vezes é retirado por meio de uma cirurgia desnecessária, antes de estar pronto, o que aumenta várias vezes os riscos de morte, que é afastado da mãe e tem a amamentação prejudicada; e com o pai, que muitas vezes não pode ver o nascimento do filho e não pode participar desse momento familiar.

A realização de procedimentos desnecessários também pode ser considerada uma forma de violência obstétrica, "Afinal sabemos que os riscos de uma cesárea são muito maiores do que o parto normal", afirma a ginecologista e obstetra Ione Rodrigues Brum, vice-presidente da Comissão de parto, abortamento e puerpério da Federação Brasileira das Associações de Ginecologia e Obstetrícia (FEBRASGO).

Segundo a obstetriz Ana Cristina Duarte, uma das principais vozes do movimento de humanização do parto no país, o cenário faz com que a cesariana marcada com antecedência seja mais vantajosa, por conta da imprevisibilidade do parto normal. "Com a cesárea marcada, não só o médico não perde tempo, como ele também não precisa desmarcar compromissos, consultas no consultórios, viagens, etc.".

Também é o que explica o obstetra e ginecologista Jorge Kuhn, professor do departamento de obstetrícia da Universidade Federal de São Paulo (UNIFESP).

Indicações de cesárea discutíveis são uma violência, afinal, a mulher confia naquele profissional e quando ele diz, por exemplo, 
que a cirurgia terá que ser feita porque o bebê está muito grande, ela acredita.

No entanto, também se pode pensar como violência obstétrica a mulher ser privada da escolha da via de parto. Isso porque culturalmente as mulheres são levadas a pensar que o parto normal é sempre a melhor escolha para ela e seu bebê. No entanto, não são informadas de forma adequada sobre as vantagens e desvantagens de cada um dos métodos. De acordo com a Doutora em Ciências da Saúde, Nilza Alves Marques Almeida, essa concepção sobre o parto normal está mudando.

Como triunfo social, a obstetrícia médica, além de manter o modelo intervencionista de assistência, passou a apontar o parto cirúrgico como uma das soluções para o problema da dor do parto normal, com base na ideia de que a mulher não é a culpada pela dor, mas sim vítima de sua própria natureza. Assim, por meio de uma cesárea eletiva, a dor do parto normal poderia ser evitada para a maioria das mulheres assistidas no setor privado, tornando-se uma intervenção, muitas vezes realizada por conveniências diversas da equipe médica, e até mesmo, da própria mulher grávida.

Quando as mulheres se sentirem enganadas por indicação de cesárea, maltratadas verbalmente, não receberem analgesia solicitada, sofrerem episiotomia sem esclarecimento e anuência, forem obrigadas a deixar o acompanhante de fora da sala de parto ou amarradas na cama ou alguém 'empurrar', subir na sua barriga, para a criança nascer”, elas podem agir legalmente. "Ela pode buscar reparação de dano material ou dano moral por meio de um advogado", explica Cavalcanti. “Todas essas práticas são reconhecidas há muito tempo pela Organização Mundial de Saúde (OMS) como prejudiciais à saúde da mãe e/ou do bebê, porém continuam a ser adotadas no Brasil."

Algo que contribuiu para as mulheres irem a luta pelos seus direitos foi presenciar a violência obstétrica na própria pele. Cometida diariamente contra as mulheres por meio de palavras, expressões de ironia, procedimentos invasivos, condutas inadequadas (mentir para a paciente quanto a sua dilatação ou vitalidade fetal, para indicar cesariana devido a interesses pessoais), coerção (parto cesárea eletivo forjando indicações que não são reais tais como macrossomia fetal, mecônio, circulares cervicais, bacia materna estreita), ameaça, entre outros e, se sentir impotente frente a tantas cenas humilhantes, contribuiu de forma decisiva para que as mulheres deixassem o anonimato e partissem em busca de justiça, é o que diz a enfermeira obstetra Clara Fróes de Oliveira Sanfelice.

Algumas mulheres já estão tomando as devidas providências quando percebem que foram vítimas de violência por parte dos profissionais da saúde. A advogada Priscila Cavalcanti conta que entrou com várias ações na justiça por conta dos maus-tratos sofridos 
por suas clientes. Além de processar o hospital e o profissional de saúde envolvido, em alguns casos o plano de saúde também é incluído na ação. "Usamos o respaldo de que o médico consta da rede credenciada e deveria ser melhor qualificado ou estar mais a par das evidências", comenta. A advogada, que se especializou nesse tipo de ações, aconselha as mulheres a tentar reverter o quadro no momento, quando isso é possível.

No entanto, apesar do grande número de ocorrências de desrespeito a mulher no momento do trabalho de parto, ainda não há no Brasil uma legislação para a violência obstétrica, e isso dificulta muito os processos. De acordo com a advogada Priscila Cavalcanti, especializada em direitos reprodutivos da mulher e sócia do escritório Cassab e Cavalcanti.

É importante perceber que, mesmo não havendo na lei brasileira a definição exata da violência obstétrica, a proteção legal contra o fato violento existe e deve ser procurada pela mulher que entende ter sofrido essa violência no período perinatal.

Tendo isso em vista, o Ministério Público Federal (MPF) decidiu instaurar um inquérito civil público para apurar esses casos, já que o número de denúncias só vem crescendo. Além disso, a Defensoria Pública de São Paulo também tem intensificado as ações para orientar as mulheres sobre a importância de denunciar os casos para a Justiça, a ouvidoria dos hospitais e os conselhos de classe, como o CRM (Conselho Regional de Medicina).

Além de fiscalizar as entidades de saúde que estão desrespeitando os direitos reprodutivos e sexuais das mulheres, o MPF pretende divulgar a ocorrência das práticas indevidas durante o trabalho de parto, bem como os direitos das parturientes. As procuradoras da República Luciana da Costa Pinto e Ana Previtalli, responsáveis pela instauração do inquérito civil público, defendem que as mulheres precisam ser informadas para que possam cobrar dos profissionais que as atendem, a assistência digna e baseada em evidências científicas já estabelecida pela OMS.

\section{Discussão}

A maior parte dos artigos pesquisados tem como foco principal explicar quais são os tipos de violência obstétrica que ocorrem no Brasil e quais são as consequências disso para a mulher. Segundo Nilza Alves Marques Almeida, Doutora em Ciências da Saúde e professora adjunto da Faculdade de Enfermagem (FEN) da Universidade Federal de Goiás (UFG), O parto normal, como um processo doloroso parece ser uma experiência tão antiga quanto a própria existência humana. A mais remota explicação conhecida para sua origem está contida na Bíblia Sagrada, no livro do "Gênesis" (3:16), onde Deus disse à mulher: "multiplicarei os 
sofrimentos de teu parto; darás à luz com dores...".1:51.

Em vista disso, se até mesmo a Bíblia Sagrada diz que a mulher deve sofrer durante o parto, é uma utopia esperar que a mulher consiga ver a violência obstétrica como algo fora do esperado. Isso porque, a mulher já entra na sala de parto com a ideia de que ela irá sentir dor e que tudo que farão com ela são procedimentos padrões, então qualquer desrespeito a ela é ignorado e tratado como normal.

Os desrespeitos sofridos pela mulher são inúmeros, no entanto, os mais citados nos artigos pesquisados são a episiotomia, uso de ocitocina sintética para acelerar o parto, a manobra de Kristeller e a tricotomia. Essas violências tem se mostrado muito comuns tanto no serviço público, tanto no privado, o que mostra que a desconsideração dos direitos da mulher não estão restritos a fatia mais pobre da população.

Além dos desacatos já citados, a afronta verbal também ocorre com grande frequência nos hospitais brasileiros. Mandar a mulher calar a boca durante o trabalho de parto, dizer que na hora de fazer ela não gritou, entre outras frases desrespeitosas são ouvidas diariamente pelas parturientes. $\mathrm{O}$ maior problema desse tipo de desacato é que por vergonha, medo ou falta de informação a mulher não o denuncia. Dessa forma, apesar de ocorrer em grande número, suas notificações ainda são poucas.
Uma violência obstétrica pouco abordada nos artigos pesquisados foi a impossibilidade da mulher escolher sua via de parto. O Brasil é o líder mundial no número de cesáreas com $52 \%$ dos partos sendo realizados por essa via, na rede privada, o índice sobe para $83 \%$, chegando a mais de 90\% em algumas maternidades. Esses números são resultado da falta de informação transmitida à mulher ainda no seu período de gravidez.

As equipes de saúde não informam de forma adequada para suas pacientes os benefícios e riscos do parto normal e do parto cesáreo. Dessa forma, as informações sobre as via do parto são retiradas de relatos de amigas e familiares que já deram a luz ou de revistas que informam superficialmente sobre o tema. Com isso, as mulheres são facilmente convencidas a fazer o que os médicos acham mais cômodo, ou seja, o parto cesáreo. Essa é também a opinião de Braulio Zorzella, ginecologista defensor do parto normal e pesquisador da área, que diz que "No Brasil, a palavra do médico é sempre a que vale mais. Mais do que a da grávida em si, por exemplo. E assim médicos influenciam - e muito - a opinião pública, colaborando para a epidemia de cesárea".

$\mathrm{O}$ fator em comum que liga todas as violências obstétricas relatadas é a falta de informação, por parte da mulher. A mulher necessita tomar as rédeas de suas decisões e começar a pesquisar sobre seus direitos e lutar 
para que eles sejam respeitados. Só assim ela vai deixar de exercer o papel de vítima e começara a ser a protagonista de suas próprias decisões. Para que isso aconteça à equipe de saúde também deve fazer sua parte, seja informando melhor a paciente sobre os procedimentos que serão realizados, seja respeitando o ser humano que está precisando de todo o carinho possível nesse momento de maior sensibilidade.

\section{Conclusão}

A ideia de que a mulher deve sofrer na hora do parto está presente na bíblia e ainda está enraizada na cultura de boa parte dos brasileiros. Dessa forma, desmistificar essa ideia e mostrar para a mulher que a violência obstétrica não é algo aceitável, ainda é um grande desafio.

\section{Referências}

ALMEIDA, Nilza Alves Marques; MEDEIROS, Marcelo; SOUZA Marta Rovery . Perspectivas de dor do parto normal de primigestas no período pré-natal. Texto Contexto Enfermagem, Florianópolis, 2012 Out-Dez; 21(4): 819-27. Disponível em: <http://www.scielo.br/pdf/tce/v21n4/12.pdf> Acesso em: 03 mai. 2015.

BARBA, Mariana Della; BARIFOUSE, Rafael. 'Desvalorização' de parto normal torna Brasil líder mundial de cesáreas. BBC Brasil, São Paulo. 15 abr. 2014. Disponível em: <http://www.bbc.co.uk/portuguese/noticias/20 14/04/140411_cesareas_principal_mdb_rb> Acesso em: 07 mai. 2015.
BÍBLIA SAGRADA. Gêneses. São Paulo (SP): Editora Ave-Maria Ltda; 2010.

BRASIL. Governo Federal. Parto do Princípio - Mulheres em Rede Pela Maternidade Ativa. Violência Obstétrica. "Parirás Com Dor". Brasil, 2012. Disponível em: $<$ http://www.senado.gov.br/comissoes/docum entos/SSCEPI/DOC\%20VCM\%20367.pdf>. Acesso em: 03 mai. 2015.

FIGUEIREDO, Nébia Maria Almeida; TYRRELL, Maria Antonieta Rubio; CARVALHO, Vilma; LEITE, Joséte Luzia. Indicadores de cuidados para o corpo que procria: ações de enfermagem no pré-trans e pósparto - uma contribuição para a prática de enfermagem obstétrica. Revista LatinoAmericana de Enfermagem, Ribeirão Preto, v.12, n.6, nov./dez. 2004. Disponível em: $<$ http://www.scielo.br/scielo.php?script=sci_a rttext\&pid=S010411692004000600009\&lng=pt\&nrm=iso\&tlng $=\mathrm{pt}>$. Acesso em: 11 mar. 2015.

MINISTÉRIO DA SAÚDE (BR), Secretaria de Atenção a Saúde, Departamento de Ações Programáticas Estratégicas. Manual técnico pré-natal e puerpério: atenção qualificada e humanizada. Brasília (DF): MS; 2005.

SANFELICE, Clara Fróes de Oliveira; ABBUD, Fernanda de Souza Freitas; PREGNOLATTO, Olívia Separavich; SILVA, Michelle Gonçalves da; SHIMO, Antonieta Keiko Kakuda. Do parto institucionalizado ao parto domiciliar.Revista de Rede de Enfermagem do Nordeste. v.15, n.2, 2014. Disponível em:

<http://www.revistarene.ufc.br/revista/index.p hp/revista/article/view/1561/pdf>. Acesso em: 11 mar. 2015.

SECRETARIA DE ESTADO DE SAÚDE DE MINAS GERAIS. Atenção ao pré-natal, parto e puerpério. 2. ed. Belo Horizonte: programa viva vida, 2006. 
TEIXEIRA, Neuma Zamariano Fanaia; PEREIRA, Wilza Rocha. Parto hospitalar experiências de mulheres da periferia de Cuibá-MT. Revista Latino-Americana de Enfermagem, Brasília, v.59, n.6, nov./dec. 2006. Disponível em: <http://www.scielo.br/scielo.php?script=sci_a rttext\&pid=S0034-71672006000600004>.

Acesso em: 11 mar. 2015. 